\title{
Study of the Main Social Problems of Tourism Development in Ethnic Villages
}

\author{
Dongyan $\mathrm{Ma}^{1, \mathrm{a}}$ Chao Zhang ${ }^{2, \mathrm{~b}}$ \\ ${ }^{1}$ Pan Zhihua College, Sichuan, China 617000 \\ ${ }^{2}$ Public management College of Sichuan University, Sichuan, China 610044 \\ amadongi@126.com, ㅎ390570519@qq.com
}

\begin{abstract}
Keywords: Ethnic villages; Tourism development; Social problems
Abstract: Tourism in ethnic villages is an inevitable choice of national area construction and rural tourism development in China, which has important and profound historical and realistic significance. But the process of tourism development of ethnic village in China is also associated with various social problems and it is particularly important to solve these prominent social problems for tourism health development in minority areas.
\end{abstract}

\section{Introduction}

Ethnic villages in ethnic minorities gathering have become the preeminent to lead the development direction of China's rural tourism in the new period for its primitively mysterious simplicity and unique ethnic customs. But at the same time of rapid development for tourism in the ethnic villages, many contradictions are increasingly exposed and sharp. In this papers, based on the deep insight into the highlight social problems of tourism developing to carry on the research and exploration, in order to provide the references and the train of thoughts for the sustained and healthy development of rural tourism.

\section{The highlight social problems and influence in the ethnic village tourism}

\section{The original national culture is excessively commercialized}

The authenticity and original nature of cultural are the foundation and the soul to carry out national tourism and is also an inexhaustible source of attracting tourists keep coming. So the "originality" national culture with original taste and flavor is the core of the development of the national tourism. But a large number of national cultures are excessive commercialization. Such as: traditional festivals and folk customs are not held in specified the place and time in accordance with traditional; Tourist souvenirs are shoddily made and have not followed the local production techniques and traditional style; Folk culture demonstration has delivered false information and so on. This has caused that the tourists are looking for and experiencing "originality" is merely "original true effect" which has deviated from "true" image, which are organized, designed and built up by the operator according to the preference of tourists, expectation and imagination. The false true that has killed national culture "true" and "false" boundaries not only misleads tourists but also causes the distortion of traditional ethnic culture and even disappears, which will increase the difficulty of the national culture protection and survival.

\section{Travel unfair income distribution}

The particularity of the tourism development in the ethnic villages lies in to use the villages with national cultural microcosm and the villagers of the national cultural heritage to as the main attractions of tourism. Therefore, the villages and the villagers should be in the center and the 
mainstream status in the tourism development and development and successfully share the achievements of tourism development. But the reality is the collusion between the establishment represented by grassroots governments and the commercial capital dominated by the developers. Through directly "legal" occupation for the interests of farmers and carve up the cake of the tourism income to make the villagers difficult to share the economic benefits of tourism development. The villagers who feel themselves used by the tourism development and exclusion to spontaneously pick up "the weapon of the weak", through the "violence" behavior such as the blocking the road of the mass 、sit-ins 、siege 、 petition 、 destruction of landscape、 beating related staffs, which led to a number of vicious violence between the villagers and local government or the developer and seriously impacted on the local social stability and healthy development of tourism.

\section{Compensation of land for tourism development is not reasonable}

When tourism in the ethnic village is developed at the same time, the land expropriation for tourism will inevitably happen. Especially in ethnic villages with rich tourist resources, the problem of villagers lost land is more prominent. At present although nearly land expropriation for all ethnic villages will give some compensation, most of compensation standards adopt "output multiplier method" of single buyout namely in accordance with the original purposes of land using for the expropriation compensation. The lack consideration for land differential rent and the opportunity cost, more not considering the cost of the land-lost farmers of transferring job and the cost of learning new skills to earn a living. In addition, tourism development has driven rapid appreciation of the village and the surrounding land and greatly improved the level of consumption. But limited compensation fees cannot meet the long-term livelihood of the farmers and makes residents life get into trouble. This may cause residents discontent for the tourism development is also growing, becoming a big social hidden trouble.

\section{The analysis of cause}

\section{Capacity limit of tourists and profit driven of operators}

The tourism purpose of that tourists travel to the national regions is to experience and understand heart impact and shock from the original true and foreign national culture to meet psychological expectations of seeking new seeking exotic、seeking for joy and seeking knowledge. But because most tourists have seeking the original true motives but have not gain the ability to" the original true " (have not enough expertise to distinguish what is" the original true " of culture). At the same time national culture after commercial packaging (excessive commercialization) is more likely to bring about huge profits for the operator. Therefore, instinct driven by profit-seeking behavior, the operators become the pseudo real creator and promoters, which furtherly build and strengthen the tourist image of the "real".

\section{Superficial and formal community participation}

Community participation is to make those community residents of excluded from the mainstream power can really be included and involved in the decision making and negotiations related to tourism, safeguarding the rights and interests of vulnerable groups, to prevent the government and developers for big conspiracy to plunder residents interests. But at present community participation is in superficial and symbolic. Community participation is only to allow local communities about the implementation plan、scheme and decision to react on a small scale or community passively to accept the task arrangement process. This kind of community participation is bound to make tourism controlled by the government or the developer rather than the community. Formal community participation makes the community residents deprived in the dominant position of tourism development and development, which is fundamentally denied the residents possibility of 
equitable sharing tourism income distribution.

\section{Land requisition compensation mechanism is not perfect}

Tourism land requisition compensation is that the states in accordance with the law levies and uses the land that is collectively owned and used by peasants and gives corresponding compensation for farmers. But the existing land compensation standard "output value times" does not contain land increment income in tourism development and non-productive losses for land-lost farmers as well as the loss for the increasing cost of the production and living caused by ground loss. Therefore, according to the compensation standard for land-lost farmers to compensate, the compensation amount is obviously low. For long-term livelihood problems about land-lost farmers to obtain new employment、 social security and social welfare do not give full considerations and corresponding system arrangements. For unskilled farmers who have lost the foundation of the survival, it is destined to their production and living difficulties.

\section{Countermeasures and suggestions}

\section{Regulate the behavior of tourism management}

Under the induction of direct economic benefit, excessive commercialization of national culture not only can't inject new elements and development opportunities for the development of national culture but also losing the first must be own cultural roots. Therefore, in order to prevent excessive commercialization of the national culture losing its core competitiveness of the development, it is necessary to regulate tourism business 、 resolutely blow and put an end to obtain short-term best interest through sacrificing culture "the true" and "quality" to exploit the behaviors of tourists, ensuring tourism products of the development to truly、accurately and objectively reflect the cultural connotation and theme, so as to achieve consistency of business objectives and culture.

\section{Guarantee the effectiveness of community participation with system}

At present, community participation in China and other developing countries can `t effectively solve the imbalance problem of tourism income distribution whose root lies in that the current system can't really make the community participation implement the community level. To solve the problems that community villagers' legal interests are violated and deprivation as a result of superficial and formal community participation, we must make the marginalized weak villagers group in the current mainstream power structure really participate in share and control decision-making of tourism development through relevant and supportive system construction. That is to say, only when the villagers truly become the leading stakeholders and management subject, they can obtain ability or potential of political game or power battle with outside the main stakeholders such as governments and developers, becoming the reality power to influence tourism development and the development and realize equitable tourism income, so as to truly safeguard the legitimate rights and interests of their own.

\section{Improve the tourism land requisition compensation mechanism}

This needs to carry on scientific research、 assessment and develop the new standard of flexible、 open and fair compensation according to market、 the value of the requisitioned land supply and demand geographic location. At the same time according to the people's income level、 price level、 the level of production and living to establish a dynamic adjustment mechanism, which makes the benefits of land expropriation process more than the loss of the whole process of land expropriation. The government should strengthen the supporting force land-lost farmers in job skills, production management、 medical treatment、social security and other aspects of support in order to guarantee long-term livelihood of farmers, thus completely solving the problem of land-lost farmers long life way. 


\section{References}

[1] Huang Xiangmin: submitted to Journal of Chinese Land and Resources Economy (2013)

[2] Le Kemin: submitted to Journal of Travel Research (2007)

[3] Ma Hui, Chen Qingde: Capitalization of national culture (people's publishing house , Beijing 2004).

[4] Zhang Chaozhi, Ma Ling, Wang Xiaoxiao: submitted to Journal of Tourism Science (2003) 